\title{
Jargon in English Parliamentary Debating and Its Implementation in English Teaching
}

\author{
Ni Kadek Ary Susandi \\ STIKES Bali (Institute of Health \\ Sciences Bali) \\ Denpasar - Indonesia \\ arysusandi.stikesbali@gmail.com
}

\author{
Furqanul Hakim \\ STKIP Yapis Dompu \\ Dompu - Indonesia \\ furqanul_hakim@yahoo.co.id
}

\author{
Ni Wayan Novi Suryati \\ STIKES Bali (Institute of Health \\ Sciences Bali) \\ Denpasar - Indonesia \\ novisuryati92@yahoo.com
}

\begin{abstract}
The fact that language changes is indisputable and inevitable. The nature of language that is very dynamic following the development of the society leads to the emergence of linguistics variation. Linguistics variation is believed to rely heavily on people's live and interactions. Hudson states (1981: 25) "the defining characteristic of each variety is the relevant relation to society - in other words, by whom, and when, the items concerned are used". The present study examines the differences in variations of the language used by the people in a particular group - the forms, meaning and function of English jargons used by University students competing in English parliamentary debating competitions held in the region Bali, West and East Nusa Tenggara, Indonesia. Jargon is a collection of words or specific terms used by a group of people, in which the words are only understood by those who joined the group (Fromkin and Rodman, 1979). The data were collected by recording the speech delivered by debaters during debating at the tournaments and interviewing the debaters to clarify the meaning and function of jargons used.The data will then be analyzed descriptively based on sociolinguistics and language variations theories, also previous related studies. This research is beneficial to increase scientific vocabularies and can be used as references for English teachers or English debate coaches to develop their students' skills in using English and/or to improve students' achievement in the field of English debating.
\end{abstract}

Keywords—component, formatting, style, styling

\section{INTRODUCTION}

Language is one of the seven elements of culture that has an important role in human life. Language became one of the main media used by humans to interact with each other. The development of human life is always accompanied by the development of the language used. From time to time the language changes and develops by adjusting human life. The changes are becoming prevalent because there is a close link between language and society. There are several possible relationships between language and society [1]. One is that the social structure may either influence or determine linguistic structure and/or behavior.

Sociolinguistics is one field of linguistic studies that specifically examine the relationship between language and society. It has been linked to two terms in this study, namely the "Socio" which means communities and "linguistic" means as language. This explanation is reinforced by Holmes (2013), in which she stated that sociolinguistics is the study of relationship between language and society.

The terms of jargon that became one of sociolinguistics study that examines the differences in variations of the language used by the people in a particular group. Jargon is words used to describe the special terms of a professional or trade group [2]. The definition explains that the jargon is a collection of words or specific terms used by a group of people where the words are only understood by those who joined the group. Meanings of words or terms have special meanings according to the agreement or the applicable provisions of the group. A group usually formed with certain objectives, where the existence of the group can be started from the similarity of the backgrounds group members. In their interaction, special words will appear in accordance with the field or background of the group was formed, in this case the legal field. In this study, the community used as research subjects is a community of English debate in Bali, West and East Nusa Tenggara - Indonesia. The selection of this community as the research sample is motivated by the increasingly widespread of English debate competition, especially in the region Kopertis VIII (Bali, West and East Nusa Tenggara). Determining jargon as a research focus was based on the initial findings of researchers who received some specific words which are understood only by the debaters in the group when they participated in the parliamentary debate in regional selection or competition.

There were some things which considered as the limitation of the study. Firstly, the research subject was only focused on debaters who compete in English debate competitions which held in the region ofKoordinaasi Perguruan Tinggi Swasta (Kopertis) VIII, including the province of Bali, West and East Nusa Tenggara. Secondly, the research period is in the year of 2016 to early 2017. Thirdly, the language media used by debaters is English, thus, the researchers only examine forms of jargon in English.

This research aimed at investigating (1) English jargons used by debaters competing in English debating competitions held in region Bali, West and East Nusa 
Tenggara in 2016, (2) the meaning of English jargons used by debaters competing in English debating competitions held in region Bali, West and East Nusa Tenggara in 2016, (3) the function of the English jargons used by debaters competing in English debating competitions held in region Bali, West and East Nusa Tenggara in 2016.

\section{REVIEW OF RELATED THEORIES}

Holmes (2013) stated that sociolinguists study the relationship between language and society. Sociolinguistics explores language in relation to society. They are interested in explaining why we speak differently in different social contexts, and they are concerned with identifying the social functions of language and the ways it is used to convey social meaning. This means that sociolinguists concerned with language as used for communication amongst different social groups of people in different social situations [3].

There are several possible relationships between language and society. One is that social structure may either influence or determine linguistic structure and/or behavior. A second possible relationship is directly opposed to the first: linguistic structure and/or behavior may either influence or determine social structure. A third possible relationship is that the influence is bi-directional: language and society may influence each other. A fourth possibility is to assume that there is no relationship at all between linguistic structure and social structure and that each is independent of the other [1].

The field of sociolinguistics in the early twentyfirst century is a mature, confident and vibrant discipline. At its core is a concern for the observable facts of language variation and principled thinking about the reasons and consequences of this variation and change. The fact that language changes is indisputable and inevitable, and it is this fact of change, spread unevenly across time and space, that leads to linguistic variation. Sociolinguistic interest in variation and change can be drawn in a straight line back to the earlier traditional concerns of dialectology and philology, which described the different varieties that make up a language and traced the historical development of particular features of vocabulary and grammar [4].

What makes one variety of language different from another is the linguistic items that it includes, so we may define a variety of language as a set of linguistic items with similar social distribution [5]. A variety may be much larger than a lay 'language', including a number of different languages". Akmajian, et al (2010) stated that no human language can be said to be fixed, uniform, unvarying. All languages show internal variation in that actual usage varies from speaker to speaker [6]. Languages constantly undergo changes, resulting in the development of different varieties of the languages. In sociolinguistics a variety, also called a lect, is a form of a language used by speakers of that language. Language varieties different from standard language that is taught in school, these are jargon, pidgin, creoles, slang, dialect and other. These varieties have their own vocabulary, grammatical rules and the way to pronounce words.

One of the language varieties that we often found in daily professional communication is jargon. According to Fromkin and Rodman (1979: 282), "jargon is words used to describe the special terms of a professional or trade group [2]. Practically every conceivable science, profession, trade, and occupation has its own set of words, some of which are considered to be "slang" and others "technical," depending on the status of the people using these "in" words. Such words are sometimes called jargon or argot".Jargon is vocabulary used by a special group or occupational class, usually only partially understood by outsiders.

Fromkin and Rodman (1979) further explained that many jargon terms pass into the standard language. Jargon spread from a narrow group until it is used and understood by a large segment of the population, similar to slang.In general, however, slang is more casual and acceptable to outsiders than jargon. Slangis more vivid than jargon, with a greater turnover in vocabulary [2].

There were several previous studies conducted about Jargon in many different languages. There were 66 jargons used by the facebook chatting community. Most of the jargons were in English, Indonesian and the mix of English-Indonesian [7]. The forms of jargon are mostly abbreviation, acronyms and phrases. The jargons were used as a tool of communication in the familiar, sarcastic and streamline communication.

Another study on jargon was conducted by Astutik (2014) in which she investigated the use of jargons in Kaskus forum and its significance as an alternativelearning material in writing motto. She examined all the threads which were categorized ashot thread posted by Kaskuser in the period of May, 1-30, 2013. The research finding showed that the forms of jargon in Kaskus forum were in lexicons, phrases and sentences. The findings also revealed that the features of jargon were in the form of abbreviation, new vocabularies, words in different meaning, words in other languages, and jargon in motto [8].

\section{METHOD}

This research was a qualitative research in which the population of the studywas debaters competing at any English debating tournaments held in the region of Bali, West and East Nusa Tenggara in 2016. Census sample was then used in this study. The data was collected into three ways: documentation (recording), observation and interview. These three techniques were triangulated to check the data validity.

Firstly, the data was collected by documenting (recording) the speech delivered by debaters during debating at the tournaments. During recording the debates, researchers also observed the language used by debaters, noted down any particular terms that need further clarification. After the debate sessions end, researchers conducted interview with the debaters to clarify the meaning 
and function of jargons used during the debate, also to gain more information on the debate. During the interview, there were more other jargons used by the debaters, and these jargons were also included as collected data.The collected data was then analyzed by reducing and classified the findings into some types of jargon. These findings were then analyzed descriptively based on sociolinguistics and language variations theories and previous related studies.

\section{FINDING AND DISCUSSION}

Studies on jargons used in English parliamentary debating have not been conducted and exposed widely especially in Indonesia. The increasingly widespread of English parliamentary debating tournaments, especially in the region of Kopertis VIII (Bali, East and West Nusa Tenggara) has put the researchers attention not only to the students' ability in debating but also the language used, specifically the English technical terms or jargons.

People often say that debating is similar to public speaking, however these two are not necessarily the same. The thing that separate debating and public speaking is the art of refutation and rebuttal. Fundamentally, a debate is a conversation between two groups who disagree, with each group trying to convince the adjudicators not only about the correctness of their position or stance but the 'irrelevance', 'absurdity' and 'irrationality' of their opponents' arguments. Debating is essentially an activity of arguing the rights and wrongs of ideas and policies. Competitive debating is a fun activity in which we examine ideas and policies with the aim of persuading people within an organized structure. Debating embodies the ideals of reasoned argument, tolerance for divergent points of view and rigorous selfexamination. It is also considered as the best way to gear up students' critical thinking and train students to speak strategically. However, like many other activities, debating has developed over time its own specialist vocabulary for otherwise simple concepts.

Although there are many different formats and kinds of debating used around the world, this study primarily discusses the practice of parliamentary debating, specifically the use of jargons in the parliamentary debating. The parliamentary debate style is the fastest growing and most widely used style of debate around the world, with parliamentary debate community in such diverse countries as Indonesia, Russia, Chile, Korea, United States, etc (Shuster and Meany, 2003). Parliamentary debate is a format of debate that involves two-person or three-person teams. This format include two competing teams (Australian, Asian and American parliamentary debate) or four competing teams (Bristish parliamentary debate) in a single debate round (Shuster and Meany, 2002).

There are three types of parliamentary debate that have been implemented widely throughout many nations in the world: British, Australian and Asian parliamentary debate. These all three are also the types of parliamentary debate that have been used mostly in English debating tournaments in the region Bali, East and West Nusa Tenggara - Indonesia. All three debating style used similar jargons, thus the findings in this study could be used as a comprehensive glossary of the most commonly used debating jargons.

There are 55 jargons found in this study and each of it is discussed as follows.

1. Chief Adjudicator

Chief Adjudicator, also known as the CA is the person responsible for ranking judges and setting the motions in the competition. He/She also responsible to resolve any judging issues. A CA is generally a very experienced debater and adjudicator selected by host institution.

2. Adjudicators

Adjudicators are the persons responsible for judging, weigh arguments and decide rankings in the house, in each round. In order to decide rankings in the house, adjudicators have to confer upon and discuss the debate among them in a spirit of cooperation and mutual respect. Adjudicators also responsible to determine the individual speaker marks, provide a verbal adjudication to the members and complete any documentation required by the debating tournament committee.

3. Government

Government is the side in favour of the motion. Also known as the proposition.

4. Opposition

Opposition is the side against the motion.

5. Opening Government (OG)

Opening government is the first team on the government side. It is responsible for presenting the case for the government, defining the motion (a policy or interpretation of the motion) that is relevant to the motion and should not attempt to restrict or shift it to another debate, presenting arguments in favour of the motion and rebutting opening opposition.

6. Prime Minister (PM)

Prime minister (PM) is the first speaker in the team of opening government. PM has the role to present a context or problem. He/she has also provide a clear and reasonable definition (i.e. debatable and within the context/spirit of the motion), set parameters of the debate (what exactly will we be talking about), provide arguments in supports of the motion, propose a solution (model if needed) and explain how the model solves the problem. Essentially, when the PM sits down, everyone should have a solid idea of what the debate will be about.

7. Opening Opposition (OO)

The opening opposition is the first team on the opposition side. It is responsible for presenting arguments against the motion and rebutting opening government.

8. Leader of Opposition (LO)

Leader of opposition (LO) is the first speaker in the team Opening Opposition (OO). LO sets up a clear 
response from the Opening Government bench that creates clash in the debate. LO rebuts the PM arguments and provides substantive arguments against the motion.

9. Deputy Prime Minister (DPM)

The DPM is the second speaker in the Opening Government team. The DPM delivers rebuttals to LO's arguments. DPM also supports the arguments made by $\mathrm{PM}$, and respond to the rebuttals from LO (refutation). DPM bring more arguments to support the motion and at the end of the speech, briefly sums up the OG case.

10. Deputy Leader of Opposition (DLO)

The DLO is the second speaker in the Opening Opposition team. DLO delivers rebuttals to OG's arguments, support the arguments made by LO and respond to the rebuttals from OG (refutation). DLO also should bring more arguments against the motion and at the end of the speech, briefly sums up the OO case.

11. Closing Government

Closing Government (CG) is the second team on the government side. $\mathrm{CG}$ is responsible for extending the government case and summating the debate in favour of the government.

12. Government Member

Government Member (GM) is the first speaker in the Closing Government team. GM rebuts the arguments from all opposing speakers that came before him/her and supports his/her team extensions.

13. Government Whip

Government Whip (GW) is the second speaker in the Closing Government team. GW delivers reply speech, summarize the entire debate and highlight the important roles of the closing government in the debate.

14. Closing Opposition

Closing Opposition is the second team on the opposition side. It is responsible for extending the opposition case and summating the debate in favour of the opposition.

15. Opposition Member

Opposition Member (OM) is the first speaker in the Closing Opposition team. OM rebuts the arguments from all opposing speakers that came before him/her and supports his/her team extensions.

16. Opposition Whip

Opposition Whip (OW) is the second speaker in the Closing Opposition team. OW delivers reply speech, summarize the entire debate and highlight the important roles of the closing government in the debate.

17. This House

This House is a term which is commonly abbreviated as "TH" usually begins the statement in a motion debate. Lexically, this phrase means "a building", but "This House" in debate means "this forum". Forum refers to all people who are in the room when the debate takes place. The example of its use in the motion is "This house believe that the Internet brings more harm than good". As pros and cons teams of the motion, each team will convince "This House" or the Forum in order to support them. They use the phrase as a persuasive terms to attract the attention of adjudicators, opponents, as well as all those who are in the debate chamber.

18. Mr. Speaker

This jargon has special significance in a debate. According to the dictionary, the term "Mr. Speaker" can be defined as persons who are talking. But in a debate this phrase refers to the adjudicators or specifically refers to the chair of the Adjudicators. They have main role to decide the winner in a debate. The purpose of a debater using the term "Mr. Speaker "is to call the attention of adjudicators for paying focus on the important points which they convey as a form of their attempt to convince the adjudicators. Examples of its use is "Mr. Speaker, when we talk about the benefits of using the internet ..........". In that sentence a debater is seeking attention of adjudicator to listen carefully the explanation about the benefits of using the Internet.

19. Madam Speaker

This jargon has the same meaning and purpose as "Mr. Speaker". There is a little difference in terms of its usage. "Madam Speaker" is only used when the adjudicators or the chief adjudicators are woman. Instead "Mr. Speaker "is used when the chief adjudicators and the adjudicators are man. If the adjudicators are male and female, then a debater usually use that term simultaneously. For example "Mr and Madam Speakers, as the prime minister I strongly believe that social media does not give any tangible benefits for students ....."

20. Chair Person

It is a designation that is addressed to someone who is in charge in the debate. The main task is to open the debate, calling debaters, and closes the debate.

21. Time Keeper

It is a designation that is addressed to someone who accompany and lead the debate. The main task of this person is controlling the time for each speaker.

22. Reply Speaker

In Austral Asian system, this term is used very often. This Jargon can be defined as "assigned replicates speaker" reiterated the summary of arguments that have been submitted previously by all the speakers in his or her team. In addition, the speaker is also tasked to convince the adjudicator that his/her team deserve to win by making a comparative arguments between both sides.

23. Affirmative is the side of the debate that supports the resolutions.

24. Negative is the side of the debate that against the resolutions; negating the affirmative team.

25. Motion

Motion is the statement of the debate. It is also the idea or policy that is disputed by teams in the debate. Usually the motion is either a policy or a statement, the truth or falsehood of which is examined in the debate. 
26. Case

Case is the argument delivered byaffirmative team for the resolution. It is usually a reference to the argumentspresented in the opening substantive / constructive speech by the affirmative side

27. Definition

Definition in Parliamentary debating means the policy or interpretation of the motion created by the opening government (OG) team in the debate. Resolutions sometimes contain terms that require explanation so that all debaters have the same understanding of their meaning(s). Definition must give a clear set up to the motion, has to be supported with logical reasoning and may not be too narrow. It must be fair, relatively unbiased and generally conform to the ordinary meaning of the words.

28. Challenge Definition

This jargon is used by Debaters to describe a condition in which the opposition team rejects the motion set up presented by the government team. The rejection is done by creating a new definition and debate set up.

29. Link

Link is a causal relationship. In debates, it is the relationship of one's argument to theopponent's position and the internal chain of reasoning in a complex argument.

30. Burden of proof

Burden of proof is a responsibility of the debater, upon delivering an argument,to provide sufficient reasoning, evident, analysis and further detail for the argument that the opponent is obliged take the issue into consideration.

31. Point of Information (POI)

Point of information, also known as a POI is a short, quick point of rebuttal made during a speech by a speaker on the opposing side.This term refers to an activity where a debater refute another debater who is speaking. This is simply done by debater from the opposing team.

32. On that point

This jargon is a term that used by debaters when asking time to respond the statements made by the ongoing speaker. They usually say "on that point" when a speaker from the opponent teams is presenting his/her ideas and arguments. The term can be meant "I have any disagreements on that point".

33. Extension

Extension is the new material brought by teams (closing government and closing opposition) in the closing half of the debate. It is expected to bring a new point of view or aspect to the debate and have at least one materially different point than the speeches before it.

34. Rebuttal

Rebuttal is the explanation of why the arguments made by the other side is wrong or irrelevant. It is a refutation of opponent's arguments.

35. Claim
A claim is a controversial statement that a debater supports or refutes with evidence and reasoning.

36. Status Quo

Literally, it means the way things are, the current policies, the current state of affairs. Normally, the proposition team tries to prove that the world with their plan / policy would be better than the status quo.

37. Case Building, this jargon use by debaters to mention an activity that is performed before a debate takes place. In this activity, the debaters are given for 15 to 30 minutes to prepare their arguments. Usually, the organizers count the time starting from the motion debate is announced.

38. Team Splits

This term means the separation of tasks within the team. Different roles in a team require them to make a strategic division of tasks in order to maximize the role for each speaker in a team.

39. One liner

This term is used by debaters to describe a condition when the debaters deliver statements without any reasoning, evident and analysis. It is also commonly known as assertion.

40. Clash

This jargon means pros and cons of arguments presented by both sides of the debate. It is the extent to which argument from different teams contradict and engage with each other. A point is considered clash, when it is connected against the point made by opponents directly, in which the arguments should clash directly with those of the other side.

41. Stance

The word is used by debaters to mention the objective or the direction of their establishments in presenting arguments. Customarily, the debaters make a public statement to begin their reasons why do they agree or disagree with the motion being debated.

42. Backstabbing

It is a term that describes a condition in which a debater made mistakes in expressing his/her ideas. The mistakes are committed in the form of a statement issued are contrary to their position both as a supporting team or an opponent.

43. Split Decision

The term refers to a condition when a different decision made by the adjudicators in determining the winning team in a debate. The final decision is decided by voting system or summing up the amount of adjudicators' voices in giving the victory to both sides.

44. Shame-shame

This jargon is used to mock arguments which considered as irrelevant or unreasonable that being delivered by the opponent speakers. The function of this jargon is one of the ways used by debaters to draw the attention of adjudicators.

45. Hear-hear 
As opposed to the jorgon 'Shame-shame', 'Hear-hear' is used to praise the arguments which considered as strong / good that are being delivered by the teammate speakers. Similar to 'Shame-shame', 'hear-hear' has the same function to draw the attention of adjudicator in an attempt to convince the adjudicator.

46. Matter

This term is used by adjudicators as an indicator for the assessment. The indicator refers to the quality of contents or arguments submitted by debaters.

47. Manner

Besides 'matter', manner is also one of assessment indicators. It refers to the skills of debaters in expressing their arguments such as gestures, intonations, clarity, attitude, etc.

48. Method

It is a specific term used as an aspect of the assessment in a debate. The aspects covers time management, organization structure of arguments, as well as whether or not the speakers fulfill their duties/roles.

49. Verbal Adjudication

Term refers to the explanation given by an adjudicator on a brief review of the debates that have taken place as well as the reasons of adjudicators in deciding the result of victory in a debate.

50. N1-Adjudicator

It is a term used in the debate to mention a candidate adjudicator who participated in a debate competition. They usually come from the representatives of each of institutions that participate in the debate competition. In some particular debate competition requires participants to register not only debaters, but must be accompanied with one candidate adjudicator. In a debate competition, they have to take the accreditation test to determine whether or not they are included in the team of adjudicators. Accreditation results determines two major categories of N1-Adjudicators: trainees and accredited adjudicators / panelists.

51. Assertion

It is when the debater make a statement without providing any analysis as to why it is true.

52. Breaking Teams

Breaking teams are all the debate teams who pass the out round, go to the next round after the preliminary rounds - octo-finals, semi-finals and so forth.

53. Breaking Adjudicator, as well as the term "breaking teams, "Breaking adjudicator refers to all adjudicator who are selected as qualified ones for judging in elimination or knockout round. Breaking adjudicators should pass through the preliminary round adjudication as done by the debate teams. During the preliminary rounds, the adjudicators also get feedback from the debaters.

\section{Social Contract}

This jargon means the duty to obey the government and the law and the right of the government to make the law arises from the contractual relationship, explicit or implied o the government and the governed or the citizens.

55. Mechanism

Mechanism is the way in which the proposition (government team) intends to implement any policy they are arguing for. Depending on the motion it may involve a discussion of various organizations and actors involved, what they would do, why they would do it and how you intend to ensure they will do it competently. For example in the debate "This House would legalize abortion" the government team would likely explain which pregnancies would be eligible for abortion and possibly other details.

The findings revealed that there were some types of jargon commonly used by the debaters participating at the English Debating tournaments in the region Bali, West and East Nusa Tenggara. These jargons were found as a single word form, compound word, as well as phrase form. The jargons showed the variations of language used by debaters in parliamentary debating.

It is very interesting to explore these jargons because they have special meanings according to the agreement or the applicable provisions of the debating community. When people from outside the debate community try to listen on experienced debaters having a conversation about debate, it almost seems like they are speaking a foreign language. It shows that jargons used in debate are not familiar to people outside the debating community, which means that these jargons have enriched the variation of English. These jargons can further be used as additional reference, both in teaching English and debating.

Teaching speaking skills could be quite challenging if teachers do not have a suitable method to teach speaking to his/her students. Teachers surely familiar with using films, board games or listening activities to make the lessons more interesting; however using jargons in parliamentary debate as additional reference in teaching English could also be implemented in the classroom teachings.

Debates inEnglish as Foreign Language (EFL)class combine many positive features that improve learner use of the language as well as other relevant skills. A class debate can be fun and challenging way to encourage class interaction, expand vocabulary, improve pronunciation and develop speaking fluency. Students will learn how to improve speaking skills by using appropriate jargons and technical terms, phrases and structures. In addition, students will also learn to use argumentative and academic English. Although jargons in parliamentary debate are found to be technical and mostly appropriate to use in debating settings, however in many cases, these jargons are also found to be used in real-life communication, especially in academic and professional settings.

In countries where English is taught as a foreign language (e.g. Indonesia), students are faced with many 
problems, preventing them from using English outside the classroom. In such cases, students in these countries need to go through some practices that make them practice English in real-life situations, such as classroom debates.

In teaching English, the debating jargons could be use as ice-breaker encouraging students to start speaking. Students will also be encouraged to integrate those jargons in their sentences or arguments, thus enhancing their ability in a making sentences correctly and thinking fast, expanding their range of vocabulary and improve their ability in using academic English.

Implementing the use of debating jargons in classroom teaching through English debating could be conducted as follows:

1. Teachers explain a simple debate mechanism to students, such as providing information on the team's position: proposition (positive/pro) and opposition (negative/con) teams

2. Teachers should further introduce the students to some important and mostly used debating jargons along with the function and meaning

3. Provide students with an interesting and debatable topic, a topic that easily generates many ideas and affects their lives directly. Draw upon their common experiences such as school, family, language learning, movies, songs, etc).A little controversy is a good thing, but mind the potential cultural differences of the class and don't risk offending anyone in the class. The topic's level of difficulty should be appropriate for students, depending on the students' English proficiency level. Easier topic can be used in debates for class with lower proficiency level, thus making it easier for students to be involved in the process and gain benefit from it.

4. Teachers should divide the class evenly. As this is might be the first time for students practicing debate, thus teachers may start the activity by surveying the opinion of students on the topic given. Then, students should be divided according to their real preference. After that, teacher should choose a group leader for each group. This leader will act as the person who organize the main ideas of his/her own team during the preparation rounds.

5. The teacher should also choose the adjudicators (judges) of the debate. 3 or more students (odd number) can be selected to evaluate the whole process and assessing each team based on certain criteria set by the teacher. Although the teacher could also involve as the adjudicator, it is encouraged that these students panel to have more role in grade both teams and decide the winner, thus allowing students to feel more independent, comfortable with the debate and adjudicating process and responsible for following rules and guidelines in debating and adjudicating.

6. Students will then asked to take several minutes (preferably around 30to 40 minutes) to brainstorm, read the debate materials and compose brief outlines and arguments. Do not let them exceeding the 40 minutes time limit in order to keep them energized and ensure that they have enough time to debate. Although students are encouraged to be independent in composing their arguments, however teacher should remain available to students during this preparation stage to offer vocabulary.

7. All students of each group should take notes when the opposing team speaks and prepare their own rebuttal towards the opposing team's arguments.

Although the role of teacher in this activity is more as a facilitator and motivator, however teacher would still need to assess the content of the debate and the students' manner in debating, such as the language use, dictions and vocabulary, grammar, etc. Teacher should also help struggling students to formulate their opinions by offering them some debating jargons, key words, or eliciting their intended meaning.

At the end of the debate, teacher have to review the main ideas, clashes appear during the debate and major speaking difficulties. After that, teacher should allow the students (adjudicator panel) to announce the winner of the debate and provide verbal adjudication to explain their reasons in determining the winner.

\section{CONCLUSION AND RECOMMENDATION}

The findings revealed that there were some types of jargon commonly used by the debaters participating at the English Debating championship in the region Bali, West and East Nusa Tenggara. These jargons were found as a single word form, compound word, as well as phrase form.

The jargons used in parliamentary debate definitely have enriched the language variations and linguistics studies that can be used as additional reference in teaching English and debating. Students will learn how to improve oral skills by using appropriate jargons and technical terms, phrases and structures, also by trying to use argumentative and academic English.

Languages constantly undergo changes, resulting in the development of different varieties of the languages. Subsequent research on the impact of these jargons towards English language is required, as well as the investigation on the possibility of these jargons pass into the standard language.

\section{References}

[1] Wardhaugh, Ronal. An Introduction to Sociolinguistics. Australia: Blackwell Publishing. 2006.

[2] Fromkin, Victoria and Rodman, Robert. An Introduction to Language ( $2^{\text {nd }}$ Edition). Journal of Linguistics. Volume 15, Issue 2. 1979. DOI: https://doi.org/10.1017/S0022226700016571

[3] Georgieva, Maria.. Introducing Sociolinguistics. United Kingdom: University of Sofia Press. 2014

[4] Stockwell, Peter. Sociolinguistics. London and New York: Routledge. 2007.

[5] Hudson, R. A. . Sociolinguistics. Cambridge: Cambridge University Press. 1980 
[6] Akmadijan, A., Demers, R.A., Farmer, A.K., Harnish, RM. Linguistics: An Introduction to Language and Communication. $\left(6^{\text {th }}\right.$
Edition).
2010
Retrived
from

https://mitpress.mit.edu/sites/default/files/9780262013758 sch 0001. pdfon the December 6, 2016

[7] Kurnia, V., Ermanto, \& Emidar. Penggunaan jargon oleh komunitas chatting facebook di kalangan mahasiswa Universitas Negeri Padang. 2013..

Retrived http://download.portalgaruda.org/article.php?article on $4^{\text {th }}$ November 2016.

[8] Astutik, W. Jargon dalam forum Kaskus dan pemanfaatannya sebagai alternatif materi pembelajaran penulisan slogan. 2014. Retrived from http://repository.unej.ac.id?bitstream?handle on $5^{\text {th }}$ November 2016. 